\title{
Energy efficiency: Behavioral contributions from around the globe
}

\author{
Beth Karlin • Marta A. R. Lopes • Rebecca Ford - Therese E Peffer
}

Published online: 17 October 2018

(C) Springer Nature B.V. 2018

While the physical and engineering sciences have been successful in delivering energy efficiency increases over the last 40 years, the speed and scale now required to meet international goals require insights and interventions that incorporate behavioral and lifestyle drivers of energy use. Understanding and incorporating human behavior and decision-making into policies and programs targeting energy efficiency is key to accelerate the transition to an energy-efficient future.

A wide range of behavioral interventions have been identified and tested to reduce energy demand. While these programs have demonstrated political and technical potential for energy efficiency, past

\section{B. Karlin $(\bowtie)$}

See Change Institute, Los Angeles, CA 90291, USA

e-mail: bkarlin@seechangeinstitute.com

\section{A. Lopes}

Polytechnic Institute of Coimbra, INESCC, Coimbra 3045-601, Portugal

R. Ford

Environmental Change Institute, Oxford University Centre for the Environment, University of Oxford, South Parks Road,

Oxford OX1 3QY, United Kingdom

\section{T. E. Peffer}

California Institute for Energy and Environment, University of California, 2087 Addison Stree, 2nd floor, Berkeley, CA 94704, US work has been critiqued for its lack of theoretical rigor; many have called for more attention to the conditions under which specific strategies are successful in impacting energy savings. As behaviorbased energy efficiency becomes increasingly ubiquitous, with a growing capacity to leverage personalized energy information, there is an urgency to ensure that these efforts are utilized to their full potential. While there is much research addressing whether behavior works, there has been little research into the more nuanced questions of how and for whom it works best. This special issue aims to address this need.

Transdisciplinary communities that have developed over the last decade are bringing together academics, policy-makers, utilities, program implementers, and evaluators to address this need. This special issue of Energy Efficiency presents 21 examples of research perspectives on energy-related behavior and its role in transitioning to a sustainable energy future. It takes a broad focus on behavior change that includes households, businesses, and governments; energy and mobility; and from singlefactor to systemic change. Specific topics addressed include attitudes towards energy efficiency (Cole 2018; Pelenur 2018), smart homes (Sanguinetti et al. 2018), multi-family and affordable housing (Guerra Santin 2018; O'Connor 2018), and transit behavior (Bobeth 2018; Scott 2018). 
Papers highlight the value of specific approaches, theories, and frameworks and also question the interconnections between drivers, barriers, and enablers of systemic change with consideration to theoretical positions. We hope that this issue serves to both introduce readers to the diversity of research within the behavioral domain of energy efficiency and provide seasoned scholars and practitioners with new insights and ideas for their work. 